\title{
Schools Collaboration: An Imperative for Tackling Inadequate Funding Challenge in Primary and Secondary Education in Nigeria
}

\author{
Ige Akindele, M
}

dele_divine@yahoo.co.uk

\section{Doi:10.5901/ajis.2013.v2n2p229}

\begin{abstract}
The persistent issue of inadequate funding of education in Nigeria makes it imperative for cost of education to be minimized and also for schools to collaborate so as to achieve the stated objectives efficiently. In this paper, the issue of schools collaboration in Nigeria is discussed with particular focus on the strategies for achieving it such as: borrowing; joint practical lessons; exchange of materials; joint and bulk purchase; collaborative teaching; agricultural investment, rentage of facilities to members of the public; as well as provision of services to neighbouring schools. The first part of the paper gives the introduction to the topic; the second part describes primary and secondary education and their purposes; the third discusses the history of inadequate funding challenge in educational system of Nigeria while the last discussed the strategies for schools collaboration in Nigeria.
\end{abstract}

Keywords: School, Collaboration, Funding, Challenge, Imperative, Primary, Secondary, Primary Education, Secondary Education, Nigeria

\section{Introduction}

Over the years, primary and secondary schools have been facing many challenges, one of these being the issue of inadequate funding, arising from the persistent limited allocation to education sector on which it depends (Aina, 2002; Durosaro, 2006; Amadi, 2007). In spite of the role of education in national development, it is expected that adequate financial provision will be made for education sector by governments, rather than the lip service being paid to it over the years. Unfortunately, allocation to education sector has been consistently low. Statistics (Federal Ministry of Education, 2007; 2009) confirm that during 2000 and 2008, allocation of government to education in Nigeria was between $8 \%$ and $14 \%$, which fell short of the $26 \%$ of annual Gross Domestic Product (GDP) recommended by UNESCO for effective funding of education in each country in the world (Akindutire \& Ekundayo, 2012). The limited finance flow to education sector, has however led to the problem of inadequate provision of infrastructural facilities in schools (Nwadiani, 1999; Owolabi, 1998; Okebukola, 2002; Saint, Hartnett \& Strassner, 2003; Wasagu, 2006).

\section{Conceptual Framework}

\subsection{Scope and Purposes of Primary and Secondary Education, in Nigeria's Context}

In Nigeria, primary education is provided for children of between the age of six and eleven years, in primary schools, which can be owned by public or private individual. When it is public owned, both the financing and management rest on government but if it is private, these rest on the individual or organization that establishes it. Primary education has duration of six years at the end of which a successful pupil will be issued a certificate of completion, after passing the required examination (i.e. Primary School Leaving Certificate). After the completion of primary education, a child is expected to proceed to secondary school to acquire additional knowledge and skills. Primary education is however expected to serve the following purposes:

- inculcate permanent literacy, numeracy and the ability to communicate effectively;

- lay a sound basis for scientific and reflective thinking;

- provide citizenship education as a basis for effective participation in and contribution to the life of the society;

- mould the character and develop sound attitude and morals in a child; 
- give child opportunities for developing manipulative skills that will enable him/her function effectively in the society within the limits of his/her capacity; and

- provide child with the basic tools for further educational advancement including preparation for trades and crafts of the locality (Federal Republic of Nigeria, 2004, p.14).

Secondary education is provided for children after primary education i.e. before tertiary education. It is aimed at developing a child better than the primary level, more so that it is obvious that primary education is insufficient for children to acquire literacy, numeracy, and communication skills (Ige, 2011; Yusuf, 2009). Such education is provided in secondary school, which can be owned by government (state or federal), individuals or community. It is divided into two phases as follows:

Junior School (JS): This is the first three years of secondary education. The curriculum at this phase is prevocational and academic in scope. Core, pre-vocational and non-prevocational subjects are included in the curriculum. The core subjects include: English Language, Mathematics, French, and a major Nigerian language other than that of the environment, Basic Science, Social Studies, Citizenship Education, and Basic Technology. The pre-vocational subjects include Agricultural Science, Business Studies, Home Economics, Local Crafts, Fine Arts, Computer Education and Music while the non-prevocational subjects include Religious Knowledge, Physical and Health Education as well as Arabic. Certification at the end of this phase depends on the performance of a student in Continuous Assessment (CA) and the results of Junior School Certificate Examination (JSCE), being coordinated by State Ministries of Education or Federal Ministry of Education (if owned by Federal Government). A child has to write the Junior School Certificate Examination (JSCE) at the end of this phase. A child with minimum number of passes in the subjects in the curriculum including English Language and Mathematics (varies across the States) qualifies to proceed to the Senior Secondary (SS) level where he/she will be trained for additional three years. A child that fails the JSCE (i.e. those without the minimum passes including English Language and Mathematics) is expected to enroll in technical college, an out-ofschool vocational training centre or an apprenticeship scheme, in line with the 6-3-3-4 system of education.

Senior School (SS): This is the next three years after Junior Secondary phase. It has wider scope than the Junior Secondary (JS) phase and aims at broadening the knowledge and skills of a student beyond the JS level and thus prepares him/her for further education. It is academic and vocational in scope. A student has to offer minimum of seven and maximum of eight subjects, comprising the six core subjects: English Language, Mathematics, a major Nigerian language, one science, an art, and a vocational subject. One or two other electives are to be selected from the art, science, technical, social science, and vocational subjects. Certification at the end of this phase depends on the performance of a student in the Continuous Assessment (CA) and Senior School Certificate Examination (SSCE), coordinated by West African Examinations Council (WAEC) and National Examinations Council (NECO). A child must obtain a minimum of five credits at two sittings including English Language and Mathematics to be able to proceed to the tertiary level of the educational system.

In Nigeria, secondary education aims at preparing an individual for:

- useful living within the society; and

- higher education.

Specifically, it aims at:

- providing all primary school leavers with the opportunity for education of higher level irrespective of sex, social status, religious or ethnic background;

- offering diversified curriculum to cater for differences in talents, opportunities, and future roles;

- providing trained manpower in applied science, technology and commerce at sub-professional grades;

- developing and promoting Nigerian languages, arts and culture in the context of the world's cultural heritage;

- $\quad$ inspiring students with a desire for self improvement and achievement of excellence;

- fostering national unity with an emphasis on the common ties that unite us in our diversity;

- raising a generation of people who can think for themselves, respect the views and feelings of others, respect the dignity of labour, appreciate those values specified under our broad national goals, and live as good citizens; and

- providing technical knowledge and vocational skills, necessary for agricultural, industrial, commercial, and economic development (Federal Republic of Nigeria, 2004) 


\subsection{Inadequate Funding Challenge in Nigeria's Educational System: Historical Perspective}

The issue of inadequate funding of schools in Nigeria is as old as western education. It is worthy of note that the initial period of western education in Nigeria, witnessed its funding under the aegis of the Christian Missionaries (Adesina, 1977). At this period, the colonial government then counted education to be outside its priority and thus did not show interest in it. In 1883, Governor Freeman, the then Governor of Lagos Colony, cited in Adesina (1977) declared:

Roads must be made, swamps filled up, the river properly staked and supported to prevent it from being washed away....A good prison must be built to guard the prisoners from escaping. A hospital must be erected and a powder magazine built and eventually we shall need some barracks for the police. Nothing has yet been undertaken by Government in the way of education, owing to the want of necessary funds (Adesina, 1977, p.6).

Owing to the lukewarm attitude of the colonial government, funding of the earliest schools was until 1872 achieved through personal donations by Christian Missionaries, their friends and acquaintances, Sunday offerings, as well as grants from their overseas Missions (Adeyemi, 1998; Adesina, 1977; Fafunwa, 1974). In what seems to be a dramatic change of mind, in 1872, the idea of grants provision started with the release of a token sum of $€ 1000$ for primary schools, which was later reduced to $€ 330$, and also to $€ 30$ for the three Missions that operated schools in Lagos Colony (i.e. Wesleyan Methodist Mission, Church Missionary Society, and Roman Catholic Mission), which was to be shared equally (Fafunwa, 1974, p.93). As further reported by Fafunwa (1974), in 1873, government voted €300 for the schools but failed to release the money. Between 1874 and 1876, annual grant of $€ 300$ was again released to the same three Missions, which increased to $€ 600$ in 1877 (Fafunwa, 1974).

The release of Education Ordinance in 1882 changed the 'status quo'. The Ordinance formalized the idea of grants provision to schools but based the release of grants on certain criteria such as organization and administrative efficiency, individuals' passes in annual examination per subject, average daily attendance and capital grants for building and maintenance (Fafunwa, 1974, p.94). Sequel to the implementation of the Ordinance, three categories of schools sprang up including the assisted schools (which received grants, based on the fulfillment of the established criteria), non-assisted schools (which were then financed through church collections and fees), and government schools (which were financed through public funds). The communities were mandated to participate by providing free labour for maintenance of school buildings and staff quarters (Ukeje, 1991, p.40). To show the extent of the poor funding of the earliest schools, the report of inspection of sixty eight (68) schools by Reverend Metcafe, the first Inspector of Schools revealed that the cost of the assisted schools was nearly $€ 5,000$ but government contributed only $€ 425$ to their maintenance (Adesina, 1977).

The complexity in the qualification for grants by various mission schools as a result of the introduction of the Ordinance, led to the increase in the grants to schools. In 1891, the annual grants to schools was reported to be $€ 1,675$ while in 1895, it was $€ 3,400$ (Adesina, 1977, p.11). In 1951, the entire Nigeria was divided into regions, following the adoption of Macpherson's Constitution. This makes the funding of schools a major role of the regional governments, which was achieved through provision of grants in aid, based on certain criteria. In the western region, Universal Primary Education (UPE) scheme was introduced in 1955, to provide free primary education for the eligible and willing children of primary school-age. This was imbibed by government of the eastern region in 1957, but collapsed two years after its introduction and implementation (Adesina, 1977). As much as the scheme recorded remarkable success in these regions, inadequate fund among other factors, hindered its effective implementation.

Significant landmark in the funding of schools in Nigeria was recorded in 1970 when government took over the ownership of schools from the Christian Missions to pave way for increased funding of schools and stop the domination of the Missions in the nation's educational system. With this development, it implies that the burden of schools' funding was taken up by government. Data in Table 1 show the analysis of Federal and State governments' expenditure on primary and secondary education in Nigeria between 1970 and 1974. 
Table 1: Federal and State Governments Capital Expenditure on Primary and Secondary Education in Nigeria: 19701974

\begin{tabular}{|l|c|c|c|c|c|}
\hline Level of Education & $1970-1971$ & $1971-1972$ & $1972-1973$ & $1973-1974$ & Total \\
\hline Primary & & & & & \\
Federal & 1.320 & 2.020 & 1.520 & 1.600 & 6.460 \\
States & 5.019 & 9.295 & 8.657 & 4.507 & 27.478 \\
Total & 6.339 & 11.315 & 10.177 & 6.107 & 33.938 \\
\hline Secondary & & & & & \\
Federal & 1.500 & 1.800 & 1.800 & 1.900 & 7.00 \\
States & 4.689 & 6.428 & 6.186 & 4.097 & 21.400 \\
Total & 6.189 & 8.228 & 7.986 & 5.997 & 28.400 \\
\hline
\end{tabular}

Source: Second National Development Plan (1970).Lagos, Nigeria: Federal Ministry of Information, Printing Division, p.246

In 1976, the Federal Government introduced Universal Primary Education (UPE) scheme, which was similar to the scheme in the western region in 1955. The scheme was meant to provide free primary education for all eligible children of primary school-age at national level. It is however noteworthy that one of the factors that led to its collapse was the issue of inadequate funding (Adesina, 1977). The advent of a civilian government in 1979 necessitated the adoption of a new constitution, which placed education in the concurrent legislative list between the federal and state governments. Consequently, one of the registered political parties in the country then (i.e. Unity Party of Nigeria) adopted 'free education at all levels' policy as one of its cardinal objectives. The States under the control of the party referred to as 'LOOBO States' (i.e. Lagos, Oyo, Ondo, Bendel, and Ogun) implemented the policy at primary and secondary levels. The situation led to the provision of free tuition, textbooks, equipment, and automatic promotion from primary to secondary schools, as well as the abolition of all forms of levies in secondary schools. Unfortunately, due to inadequate funding, the policy collapsed and fee was eventually introduced in schools. The growth in the number and enrollment of schools without corresponding provision of adequate infrastructural facilities, led to a decline in the standard of education. A lot of mushrooms primary and secondary schools sprang up then. Many of among such schools operated under dismal environment. Both the federal, state, and local governments have been involved in the funding of primary and secondary schools in Nigeria. The state government controls and fund secondary schools (except the Federal Unity Schools) while Federal Government provides funds for the primary schools under the control of the States' Universal Basic Education Board (SUBEB). It is however not a gainsaying that in spite of the expenditure of states, Education Trust Fund (ETF), and Federal Government on primary and secondary schools in Nigeria, many schools are still crying for government attention in Nigeria.

\subsection{Schools Collaboration Concept}

The word 'collaboration' takes its root from the verb 'collaborate'. According to Oxford Advanced Dictionary of English, the word 'collaborate' means 'to work jointly on an activity or programme'. There is schools' collaboration when two or more schools team up to work jointly on an activity or programme. Schools' collaboration can be best described as the coming together of two or more schools, to share ideas, policies, programmes, and most importantly work together to solve their problems so that the objectives of the schools can be realized effectively and efficiently. The idea of schools' collaboration stems from the fact that a school is bedeviled with myriad of problems, which might proved difficult to be solved by available resources. Since a problem can be better and quickly solved when two or more individuals share ideas and brainstorm on it, it is imperative that two or more schools should come together to solve their problems, such as inadequate fund, teachers, infrastructural facilities, and others more so that the resources from government to schools these days are limited.

\subsection{Strategies for Schools Collaboration in Nigeria}

It is imperative for a school to find solution to its problems if the stated objectives will be achieved. Schools facing 
funding challenge can resort to:

Borrowing: Over the years, it has been the habit of some State Governments in Nigeria to establish 'Science Centres' in each Local Government Area or Education Zone in their respective States. Such 'Science Centres' are usually equipped with adequate and relevant equipment, chemicals and teachers. They are also meant to provide succour to the neighbouring schools when they need science equipment, chemicals, and other science materials. A school that lacks equipment in any of the science subjects can resort to borrowing from the neighbouring schools having excess of such equipment, including the science centre (if it exists in the area). Letter of requisition needs to be prepared and sent to the Principal of such school whose equipment is to be borrowed for this to be formalized. Materials borrowed should also be documented and returned in good condition to make them available for other schools that may need them in future. A school with inadequate laboratory equipment and chemicals can also borrow from the neighbouring school(s) having excess. In Nigeria, the conduct of practical examination in subjects such as Biology, Chemistry, Physics, and Agricultural Science precedes the theory examinations during the Senior School Certificate Examination (SSCE). A lot of equipment and chemicals must be provided in the laboratories to cope with the demands of these practicals. What can be noticed in schools is a situation where schools Principals/Vice-Principals have to move from one school to another and on their knee, to get the required equipment and chemicals to be able to conduct hitch-free practical for their students and prepare them for success in the examinations.

Joint Practical Lessons: In a secondary school, Laboratory is an integral part of science teaching. Owoeye (2000) admitted that the success of science subject depends on its provision. Daramola (1985) also agrees that it plays important roles in technological oriented science curriculum and provides student, the opportunity to engage in investigation and inquiry. Inspite of its role in science teaching, many schools in Nigeria lack science laboratory while available laboratories in many schools, are characterized by inadequate and obsolete equipment (Yusuf, 2008). A school without science laboratory can however arrange its students to join students in other neighbouring school (s) having this, for joint practical lesson in the particular science subject (s). For this to be practicable, science teachers of both schools should harmonise their scheme of work so that no group of students would be left behind.

Exchange of Materials: There have been complaints from most Principals that the little fund they receive from government as running grants is inadequate to run the school appropriately. In most States, government frowns at illegal/extra collections from students, which could have made it possible for them to finance the conduct of the practical examinations easily. To tackle this problem, excess science equipment in a particular school can be loaned to schools having inadequacy of equipment. The equipment and chemicals/reagents for practical can also be exchanged between two schools. For instance, if a school has excess of a particular science equipment/chemical but lacks other needed equipment/chemicals, while another school has excess of the equipment and chemical which the first school lacks, School A can give out some of its excess equipment/chemicals in exchange for those equipment/chemical in excess in school B.

Collaborative Teaching: Inadequate teachers, has been another challenge facing educational system in Nigeria. Many schools in Nigeria are plague by lack of/ and inadequate teachers in many subjects, particularly the core ones such as English Language, Mathematics, and sciences (Federal Ministry of Education, 2007; 2009; Lassa, 1998). A school lacking teacher in a particular subject can team up with neighbouring school(s) to share teachers on the subjects. A school with excess teachers can allow some of the excess teachers to teach students in those schools lacking teachers in the particular subject(s). In another way, students of schools lacking teachers can team up with students of those having teachers in a subject for 'joint teaching'.

Joint and Bulk Purchase: In a school setting, some items are needed to run the school daily. In particular, a boarding school requires adequate food items to feed the students daily. The cost of purchasing these items can however be a yoke for schools, particularly where they have higher population. Ige (2000) suggested that a school can team up with other neighbouring school(s) for direct purchase of stationery, food items, and other materials needed to be purchased, which can reduce the transportation/carriage cost and the cost that would arise due to inflation of prices by middlemen. The cash discount that may possibly be granted for purchasing such items in large quantity is another advantage.

Obtaining Loan: It is not a gainsaying that schools differ in terms of financial capability. While some schools have high enrolment, some have low enrolment. In Nigeria, one of the conditions for release of running grants to schools is the size of enrolment. The higher the enrolment of a school therefore, the higher would be the running grant of such school, while the lower the enrolment, the lower would be the running grants. Some schools might also have agricultural proceeds to sell to members of the public to raise income. In terms of availability of fund therefore, such schools have 
advantage over others that lack facilities. A financially buoyant school can thus give out money as loan to a neighbouring school during the period of financial crisis or emergency such as examination, disaster e.gs roof blown up by rainstorm.

Agricultural Investment: Agriculture can be a means through which a school can raise additional income, to augment the running grant from government. Schools such as those in the difficult terrains (i.e. on rock, river side) and those having limited land can be constrained from embarking on wide scale agriculture. Such schools can thus join any of the schools on good terrain and those having excess land for joint agricultural venture, to plant cash and food crops as well as embark on mechanized farming. At the end, proceeds from such agricultural ventures can be sold to members of the public while the income shared by the schools.

Rentage of Facilities to Members of the Public: A school having electrical gadgets such as Public Address System, Generator, among others can rent these out or release them to neignbouring schools during the time of need, to save cost of purchasing new gadgets. Where a school is having large multipurpose hall, it can also be rented out or temporarily given to other neighbouring schools to use it for important ceremony (ies) at reduced price.

Provision of Services to Neighbouring School (s): In addition, technical and vocational subjects such as Metal Work, Basic Technology, Technical Drawing, Woodwork, are offered in the secondary education curriculum in Nigeria. Many teachers that specialize in these subjects abound in secondary schools. Such teachers could however be of assistance to other schools during the time of need. A school that wishes to embark on project such as construction of building, furniture but lack teachers in these subjects can contact those having such teachers, for assistance in the area of the drawing of building plan, painting of building, construction of furniture, and a host of others. This can help to save the cost that would have to be borne if professionals are hired from outside.

\section{Summary and Conclusion}

Money is believed to be the 'vehicle of evangelism'. Adequate fund is needed by a school to tackle school's challenges such as payment of salaries and allowances of teachers, provision of infrastructural facilities, running school on daily basis, as well as meeting the contingencies. Unfortunately, inadequate fund has been a feature of educational system in Nigeria over the years. The limited allocation to education sector makes schools to receive less running grant from government. It thus behooves on schools' administrators to devise strategies for combating this inadequate funding challenge and thus achieve the schools' objectives. Since a problem can be better solved when two or more individuals come together to share ideas and act together, collaboration of schools can go a long way to enable schools tackle this challenge. In this paper, how two or more schools can collaborate to solve the inadequate fund challenge, was examined. It is hopeful that if the measures are adopted, not only will the challenge be tackled, the achievement of the present Universal Basic Education (UBE) objectives in Nigeria will be reality and not 'mirage'.

\section{References}

Adesina, S. (1977). Planning and educational development in Nigeria. Lagos, Nigeria: Educational Industries Limited

Aina, O. (2002). Alternative modes of financing higher education in Nigeria and implications for University governance. Africa Development, 27(1\&2): 236-262

Akindutire, I.O., \& Ekundayo, H.T.(2012). Teacher education in a democratic Nigeria: challenges and the way forward. International Research Journal Review, 3(5): 429-435

Amadi, M.N. (2007). Funding initiatives in higher education, J.B. Babalola., G.O. Akpa. A.O.

Ayeni, S.O. Adedeji (Eds). Access, Equity and Quality in Higher Education. NAEAP publications, 543-5554

Daramola, S.O. (1985). The role of science laboratory in a technologically oriented science curriculum. Ilorin Journal of Education, 5: 4849

Durosaro, D.O. (2006). Teacher education in Nigeria: Past, present and future challenges. The Pacesetter Journal of oyo State College of Education, 13(1): 44-54

Fafunwa, A.B. (1974). History of education in Nigeria. U.K: George Allen \& Urwin Limited.

Federal Republic of Nigeria (1970). Second National Development Plan. Lagos, Nigeria: Federal Ministry of Information, Printing Division, p.246

Federal Republic of Nigeria (2004). National Policy on Education (Revised). Abuja, Nigeria: Federal Government Press

Federal Ministry of Education (2007). Statistics of education in Nigeria: 1999-2005. Abuja, Nigeria: Federal Government Press

Federal Ministry of Education (2009). The state of education in Nigeria. Abuja, Nigeria: Federal Inspectorate Service

Ige, A.M. (2000). Cost reduction strategies in secondary educational institutions settings. International Journal of Educational Planning and Administration, 1(1): 49-55 
Lassa, P. (1998).Teacher Production: A focus on Nigeria. In UNESCO (Ed). The state of education in Nigeria. Lagos, Nigeria: NESCO Regional Office.

Nwadiani, M. (1999). Dystrophies in higher education: Nigerian experience. Higher Education Review, 31 (3): 17-26

Okebukola, P (2002). The state of university education in Nigeria. Abuja, Nigeria: National Universities Commission.

Oxford Dictionary of Current English (2006 edition); Oxford, New York: Oxford University Press

Owoeye, J.S. (2000). The Effect of integration of location, facilities and class size on academic achievement of secondary schools students' in Ekiti state. Unpublished PhD Thesis, University of Ibadan, Nigeria

Owolabi, S. (1998). Dimensions of educational poverty in Nigeria. African Journal of Educational Management, 6: 197-208

Saint, W., Hartnett, T.A., \& Strassner, E (2003). Higher education in Nigeria: A status report. Higher Education Policy, 16: $259-281$

Wasagu, M.A. (2006, 28th March-1st April). Presidential address at the opening ceremony of Science Teachers Association of Nigeria (STAN) Primary Science Workshop, held at Uyo, Akwa Ibom State, Nigeria

Yusuf, A.A. (2008).Basic/fundamental techniques for a Biology laboratory and laboratory Animal house keeping. basic laboratory techniques and procedures for laboratory assistants and attendants. A Training Manual of Nigeria Institute of Science Laboratory Technology (NISLT). 
